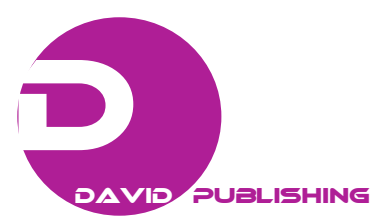

\title{
Obtaining Porosity of Concrete Using X-ray Microtomography or Digital Scanner
}

\author{
Jose Renato de Castro Pessoa ${ }^{*}$, Joel Sanchez Dominguez, Gil de Carvalho and Joaquim Teixeira de Assis \\ Politechnical Institute of Rio de Janeiro State University, Nova Friburgo 28625-570, Brazil
}

Received: March 14, 2014 / Accepted: April 08, 2014 / Published: April 25, 2014.

\begin{abstract}
The aim of this work is to determine the porosity of concrete by means of two NDT (non-destructive testing) using digital images. In one test, the images were obtained through X-ray microtomography and for another test via digital scanner. In both of the tests, the images were processed using techniques of mathematical morphology and pixel processing. For both NDT, it was used concrete samples with 20-30 MPa of compressive strength. The results for the porosity were compared with results obtained by the standard test proposed by NBR (Norma Brasileira) 9778 (2005) showing the compatibility between two studied methods and pattern method.
\end{abstract}

Key words: Concrete porosity, X-ray microtomographic, images processing, matematical morfology.

\section{Introduction}

The porosity of a material can be thought as a property to present pores or voids and is symbolized by the fraction of the total mass of a sample that is occupied by pores or voids. In the concrete matrix, the porosity has a great influence on their mechanical strength, workability and durability. By the previous becomes important to develop methods to regulate not only the index of voids, but besides the physical characteristics and placement of the pores.

Different methods for determining the porosity of concrete does not always result in similar values. That is because traditional testing methods for determining this index usually change the structure of the cement paste, especially when they involve the addition or emulsion of liquid [1]. An example is the use of mercury intrusion to study the pore system of the cement paste, admitting that the pores will be narrowing with increasing depth, whereas in fact, some pores have a narrower aperture, thus distorting

\footnotetext{
*Corresponding author: Jose Renato de Castro Pessoa, Professor, research fields: concrete technology, materials characterization, tomography, images processing and structural analyzes. E-mail: jpessoa@iprj.uerj.br.
}

the value of the porosity determined by this method [2]. Systematization of methods to determine the porosity of some materials has been the object of the works being produced over time. Some of these methods use high-quality images and work with techniques and programs of digital image processing.

In this study, two NDT (non-destructive testing) to obtain the porosity of concrete were used. In the first, NDT X-ray microtomography was used with the purpose of being acquired digital images of the internal structure of the test-bodies. In the second, NDT a commercial scanner was used to directly scan the surfaces of cross sections of these tests-bodies. For both tests, the images were digitally processed to measure the porosity of the material. This digital image processing consisted mainly in performing mathematical morphology operations and processing of pixels.

The average surface porosity found in the concrete were compared with the volumetric porosity detected using the Brazilian standard NBR (Norma Brasileira) 9778 (2005) [3]. This method is a pattern for this kind of measures; tests with the standard method were performed in the Department of Materials Engineering, 
Federal University of São Carlos SP. In Section 2, we are presented some basics related to image processing and mathematical morphology; the Section 3 showing the experimental procedure and commented the performed tests and the Section 4 presented the obtained results and conclusions.

\section{Images Processing}

Understanding an image as a compact way to represent a lot of information, in a system of image processing this information may go through diverse forms of representation depending on the purpose defined for the application. The first step of the system is the acquisition of an image, where one type of sensor can be used for digitizing. The sensor may be a scanner, a TV camera, a photo camera, a CT scan, etc.. The nature of the sensor and the image it producing is determined by the application.

In image processing, morphological study focuses on the geometric characteristics of the images and applies in many areas of image processing, such as filtering, segmentation, enhancement and others [4].

The main idea of mathematical morphology consists of sets of picture elements (pixels), which are placed in groups, representing a 2D structure (shape), and over which mathematical operations are carried to highlight specific aspects of the forms so that they can be recognized and measures [5].

A mathematical morphology can be translated as the application of mathematical definitions and principles emphasizing specific aspects of the forms allowing them to be counted or recognized. It is a methodology for the description of operators, and its base is to extract from unknown image its geometry and topology by using the transformation of another completely defined image, called structuring element image. The main applications of mathematical morphology are in the process of noise filtering, segmentation parts, skeletization, etc. [6].

\section{Experimental Procedure}

The test-bodies were molded in concrete with $20 \mathrm{MPa}$ and concrete with $30 \mathrm{MPa}$ compressive strength, the materials were collected in a cement truck. Table 1 shows the dimensions of cylindrical test-bodies used in each testing.

The bodies were originally molded with $200 \mathrm{~mm} \times$ $100 \mathrm{~mm}$, and which were cut to build the smaller bodies.

\subsection{Volumetric Porosity by NBR 9778}

The procedures for performing this test are described in detail in the Brazilian standard NBR 778 (2005). The method is based on the technique of mercury porosimetry. This technique consists essentially in measuring the extent of mercury penetration into an evacuated solid as a function of the applied hydrostatic pressure. The use of these techniques requires specialized equipment and the proper handling of mercury for it to be a contaminant element. Table 2 shows the values of volumetric porosity obtained in the test for each of the studied samples.

\subsection{Surface Porosity by Microtomography}

To accomplish, the X-ray microtomography was used a compact instrument for high-resolution microtomography $(14.97 \mu \mathrm{m})$ from Sky Scan, model 1172. This system has a variable size of focus depending on the power applied. Table 3 summarizes the main characteristics of this equipment.

In order to minimize distorting effects of $\mathrm{CT}$ due to the beam hardening effect [7], two filters $(\mathrm{Al}+\mathrm{Cu})$ were used, placed between the radiation source and the object to be inspected. Fig. 1 shows the CT

Table 1 Dimensions for cylindrical test-bodies.

\begin{tabular}{lll}
\hline Method & Diameter $(\mathrm{mm})$ & Height $(\mathrm{mm})$ \\
\hline NBR 9778 & 100 & 200 \\
Micro CT & 25 & 50 \\
Scanner & 100 & 15 \\
\hline
\end{tabular}

Table 2 Values of volumetric porosity with NBR 778.

\begin{tabular}{ll}
\hline Concrete & Volumetric porosity (\%) \\
\hline $20 \mathrm{MPa}$ & 1.9 \\
$30 \mathrm{MPa}$ & 2.1 \\
\hline
\end{tabular}


Table 3 Main features of the Sky Scan 1172.

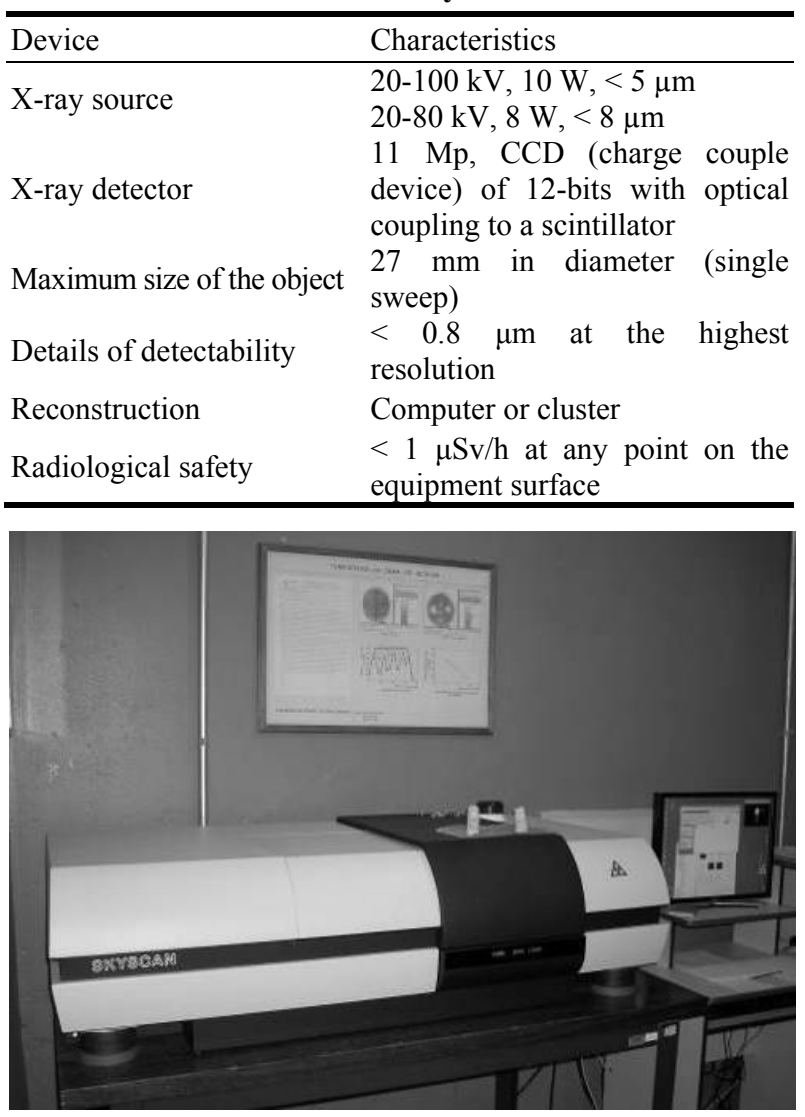

Fig. 1 CT scanner Sky Scan 1172.

scanner used in the research. Due to the CT scanner used can only measure samples of concrete with small diameter, we used 7 cylindrical test-bodies whose dimensions were specified in Table 1.

A program was developed in MATLAB $^{\circledR}$ to read each generated image and determine the area of voids to obtain the surface porosity. In this program, only two parameters required user intervention the contrast intensity and the binarization threshold. These parameters were modified for each set of processed images. For each body-test, an average of 1,000 images were obtained. Each image was adjusted in contrast, binarized and filtered using morphological closing operation (dilatation followed by erosion) with circular structuring element with 2 pixels of radius to remove isolated points interpreted as noise. In the $2 \mathrm{D}$ result, the empty spaces images were counted. The Fig. 2 showed the sequence of operations of the developed program.

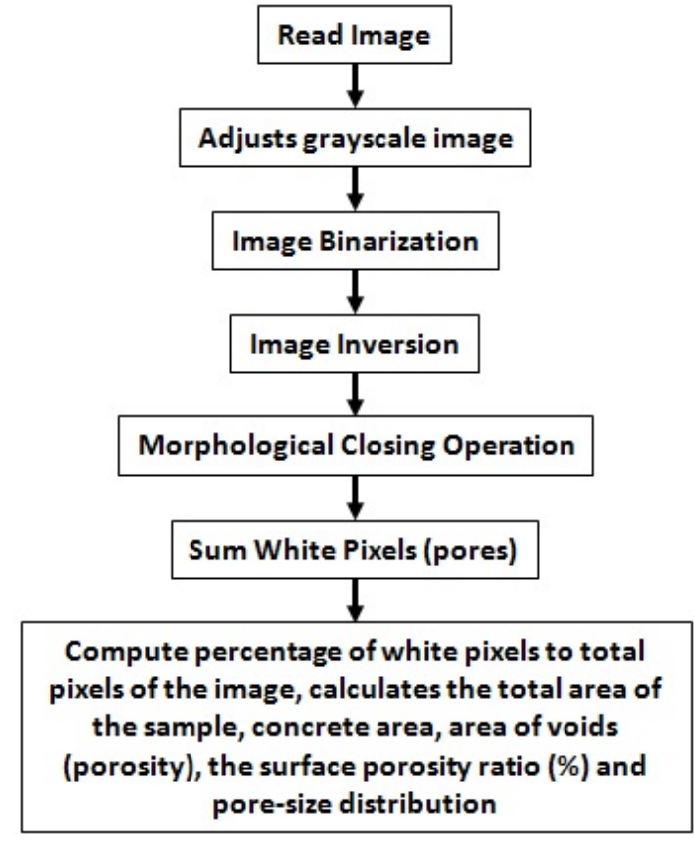

Fig. 2 Flow diagram of software to process tomography images.

The Eq. (1) was used to compute the surface porosity of concrete.

$$
P(\%)=\frac{A_{T}-A_{c}}{A_{T}} * 100
$$

where, $P$ represented the superficial porosity and $A_{T}$, $A_{C}$ are total area and concrete area, respectively.

Fig. 3 shows a cross-section with two cuts from an image reconstructed from radiographs obtained.

Fig. 4 shows the processing stages of reconstructed slice acquired in microtomography process.

Tables 4 and 5 show the results achieved with this method for the samples tested with compressive strength of $20 \mathrm{MPa}$ and $30 \mathrm{MPa}$, respectively. The

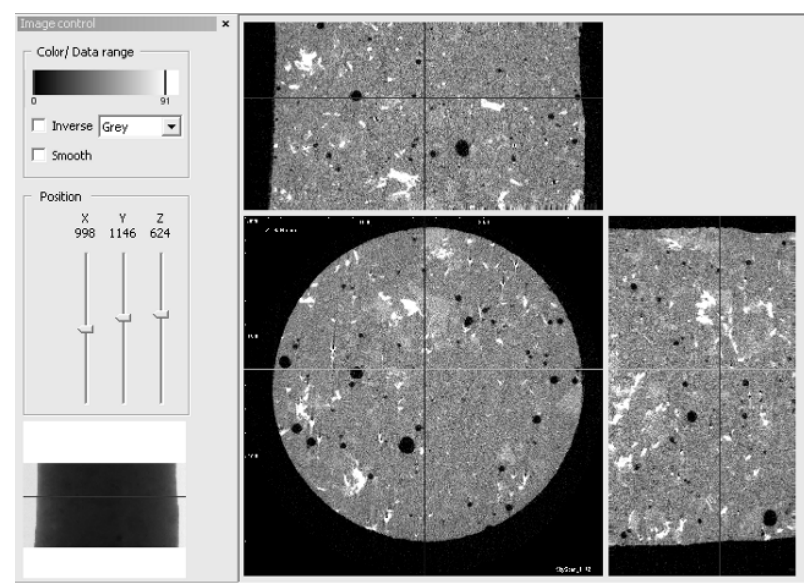

Fig. 3 Two cuts from a reconstructed images. 


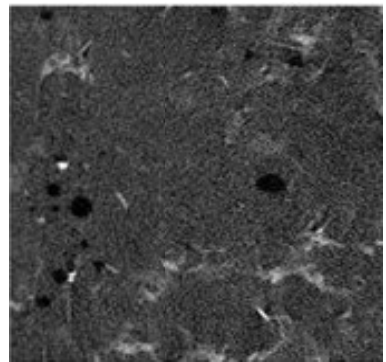

(a)

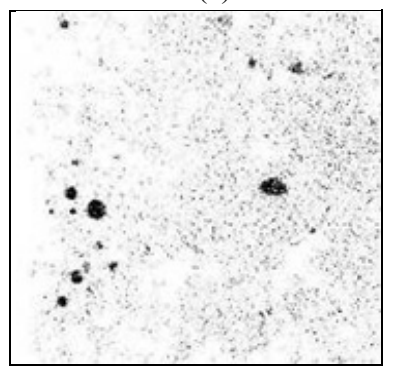

(c)

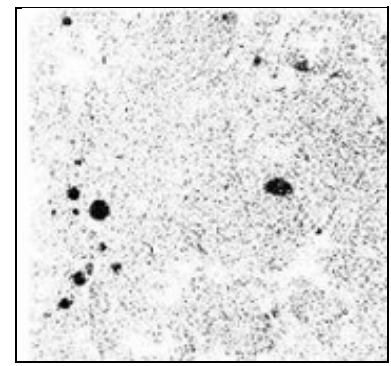

(b)

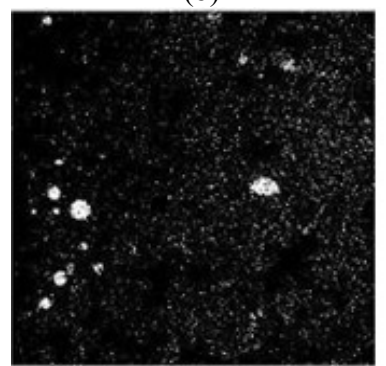

(d)

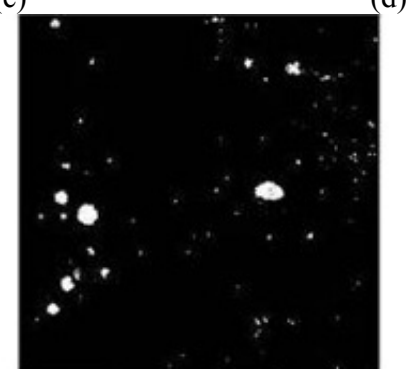

(e)

Fig. 4 Processing stages of tomography images: (a) Original image; (b) Ajusted image; (c) Binarized image; (d) Inverted image and (e) Filtered image.

Table 4 Surface porosity for bodies of 20 Mpa concrete.

\begin{tabular}{llll}
\hline Test-body & Images & $\begin{array}{l}\text { Surface porosity } \\
(\%)\end{array}$ & $\begin{array}{l}\text { Standard deviation } \\
(\%)\end{array}$ \\
\hline 1 & 1,045 & 1.1 & 0.57 \\
2 & 1,044 & 0.8 & 0.42 \\
3 & 1,044 & 1.4 & 0.97 \\
4 & 1,044 & 0.6 & 0.52 \\
5 & 1,046 & 1.2 & 1.27 \\
6 & 1,046 & 0.9 & 0.77 \\
7 & 1,046 & 1.4 & 1.06 \\
\hline
\end{tabular}

Table 5 Surface porosity for bodies of 30 Mpa concrete.

\begin{tabular}{llll}
\hline Test-body & Images & $\begin{array}{l}\text { Surface porosity } \\
(\%)\end{array}$ & $\begin{array}{l}\text { Standard deviation } \\
(\%)\end{array}$ \\
\hline 1 & 1,046 & 1.0 & 0.80 \\
2 & 1,046 & 1.2 & 0.55 \\
3 & 1,046 & 2.3 & 1.62 \\
4 & 962 & 0.9 & 0.57 \\
5 & 1,046 & 2.5 & 1.26 \\
6 & 1,046 & 1.3 & 0.67 \\
7 & 1,046 & 2.2 & 0.95 \\
\hline
\end{tabular}

Table 6 Porosity values obtained with microCT.

\begin{tabular}{lll}
\hline Concrete & Number of images & Volumetric porosity (\%) \\
$20 \mathrm{MPa}$ & 7,315 & 1.0 \\
$30 \mathrm{MPa}$ & 7,238 & 1.6 \\
\hline
\end{tabular}

Tables 4 and 5 columns represent the sample number, the number of images analyzed, the surface porosity and the standard deviation between images of the same test-body.

The standard deviation of about $1 \%$ of all samples studied indicate the similarity of the porosity values calculated for each slice of the reconstruction belonging the same test-body. Table 6 shows the total mean surface porosity for the two series of test-bodies.

\subsection{Surface Porosity by Scanner}

Forty-two circular surfaces measuring $100 \mathrm{~mm}$ in diameter acquired from cylindrical test-bodies of $100 \mathrm{~mm}$ diameter by $15 \mathrm{~mm}$ in height were used for each type of concrete. On each surface were acquired four square images measuring $25 \mathrm{~mm}$ side, totaling 168 images to be analyzed for each particular type of concrete. A shield made with transparent plastic with openings in the reading area was used so the concrete surface, which did not damage the scanner glass. Fig. 5 shows an example of the concrete surface to be scanned.

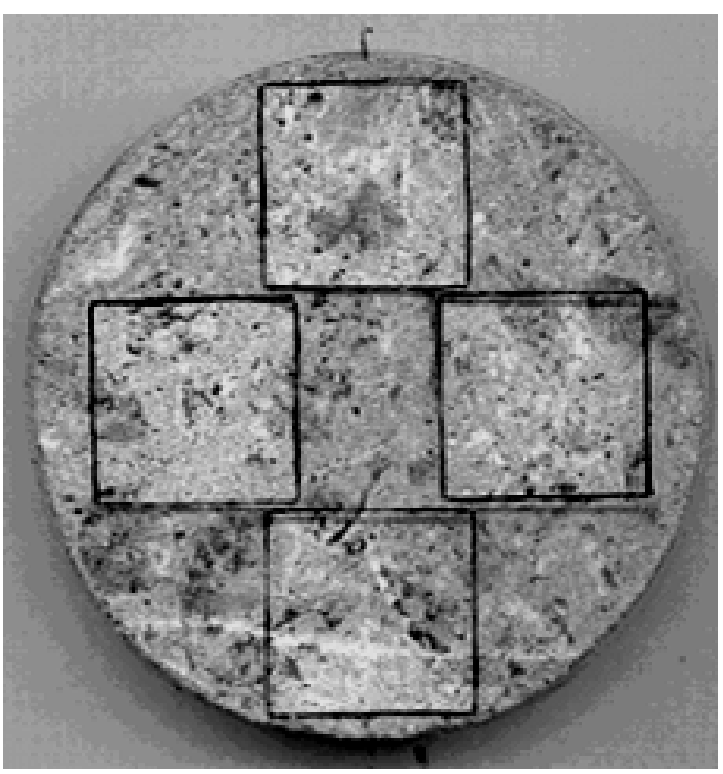

Fig. 5 Concrete surface to be scanned. 
The images were scanned using a multifunctional EPSON TX200 and digitized with 2400 dpi of resolution. To crop the interest areas, the tools available on a typical software was used to manipulate images how to Paint or Photoshop. A program was developed in MATLAB ${ }^{\circledR}$ to read the cropped images and process them in order to determine which areas are empty. Each image was read and subsequently separated into its HSV (Hue, Saturation and Value mode color) components, since the images obtained by the scanner are in RGB (Red, Green and Blue color mode) and not grayscale as in the case of images obtained by microtomography. HSV was chosen over the standard RGB because this was not possible to clearly identify the pores in any of its layers, R, G or B. Making use of the HSV standard, the layer $\mathrm{V}$ was chosen for processing; due to this layer had the best representation of pores in the image. Each image was converted to HSV pattern, extracted V layer; then V layer was adjusted in contrast, binarized and filtered using morphological closing operation. In the result image, the empty spaces were counted. The Fig. 6 showed the sequence of operations of the developed program to process the cropped images acquired with the scanner.

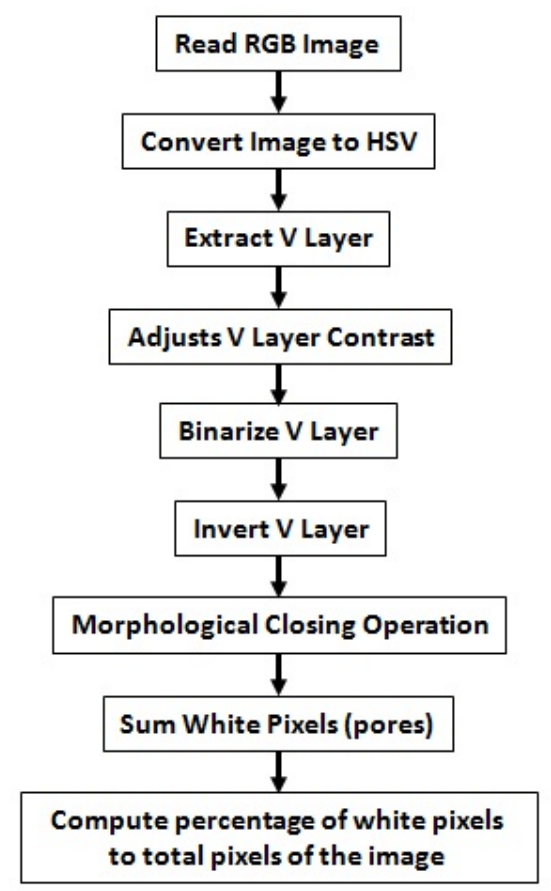

Fig. 6 Flow diagram of software to process scanned images.
In this program, it also the parameters contrast intensity and binarization threshold requiring user intervention. These parameters were adjusted for each group of processing images. Fig. 7 shows the processing stages of the image acquired cutting scanned image.

With the same structure of Tables 4 and 5, Tables 7 and 8 shows the results achieved with this method for both types of concrete.

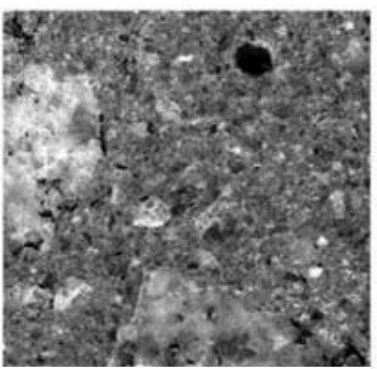

(a)

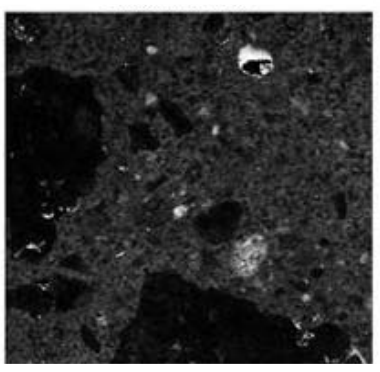

(c)

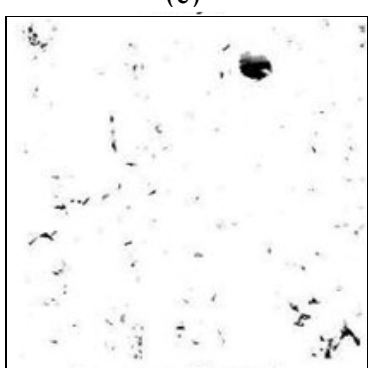

(e)

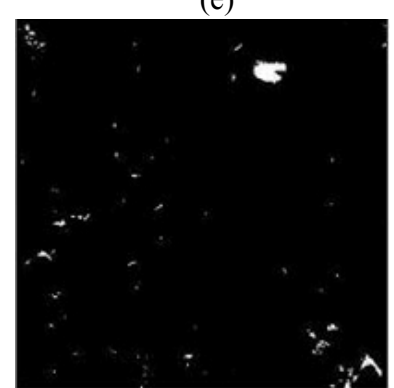

(g)

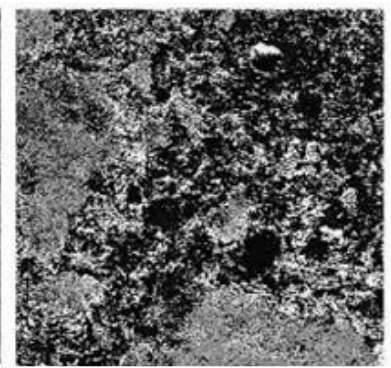

(b)

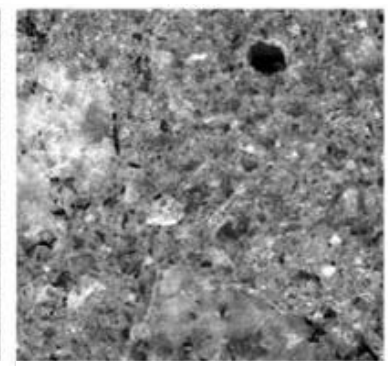

(d)
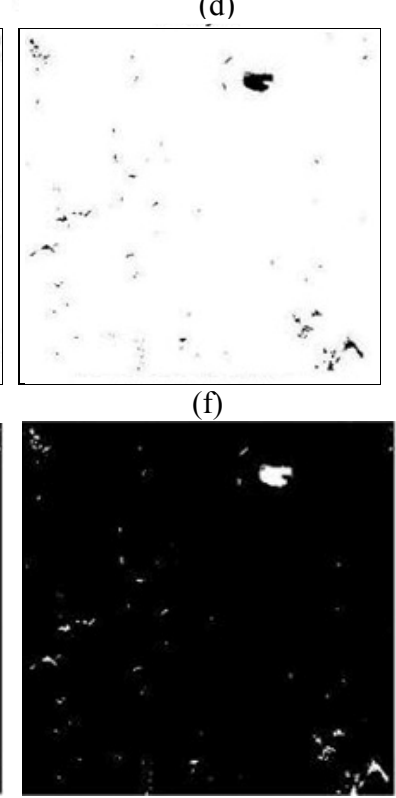

(h)

Fig. 7 Processing stages of scanned images: (a) Original image; (b) H layer; (c) S layer; (d) V layer; (e) Ajusted image; (f) Binarized image; (g) Inverted image and (h) Filtered image. 
Table 7 Surface porosity for bodies of 20 Mpa concrete.

\begin{tabular}{llll}
\hline Test-body & Images & $\begin{array}{l}\text { Surface porosity } \\
(\%)\end{array}$ & $\begin{array}{l}\text { Standard deviation } \\
(\%)\end{array}$ \\
\hline 1 & 24 & 1.08 & 0.53 \\
2 & 24 & 1.67 & 0.82 \\
3 & 24 & 1.46 & 0.45 \\
4 & 24 & 2.28 & 1.46 \\
5 & 24 & 2.03 & 1.81 \\
6 & 24 & 1.63 & 0.57 \\
7 & 24 & 1.79 & 0.73 \\
\hline
\end{tabular}

Table 8 Surface porosity for bodies of 30 Mpa concrete.

\begin{tabular}{llll}
\hline Test-body & Images & $\begin{array}{l}\text { Surface porosity } \\
(\%)\end{array}$ & $\begin{array}{l}\text { Standard deviation } \\
(\%)\end{array}$ \\
\hline 1 & 24 & 1.04 & 0.48 \\
2 & 24 & 1.15 & 0.56 \\
3 & 24 & 1.65 & 0.58 \\
4 & 24 & 1.98 & 0.71 \\
5 & 24 & 1.58 & 0.53 \\
6 & 24 & 1.64 & 0.53 \\
7 & 24 & 1.92 & 0.71 \\
\hline
\end{tabular}

Table 9 shows the total mean surface porosity for the two series of test-bodies.

\section{Analysis of Results and Conclussions}

Table 10 summarizes a comparison between the results obtained by the two methods discussed in this work and the results of the test prescribed in NBR 9778.

Considering that, the linear surface porosity and volumetric porosity must be equivalent. The average surface porosity found using microtomography and scanner can be compared with the volume porosity found in the samples of concrete, prepared with the same batch and tested by the method shown in NBR 9778. Table 10 shows some differences between the values found for the concrete porosity by different methods; these possible differences were also commented by other authors [7].

Analyzing the two methods used to measure the concrete surface porosity, similar results were found in the $30 \mathrm{MPa}$ concrete and difference values for the $20 \mathrm{MPa}$ concrete. These differences could be due to the selection of parameters contrast intensity and binarization by the program user. With this selection,
Table 9 Porosity values obtained with scanner.

\begin{tabular}{|c|c|c|c|}
\hline Concrete & \multicolumn{2}{|c|}{ Number of images } & Volumetric porosity (\%) \\
\hline $20 \mathrm{MPa}$ & \multicolumn{2}{|l|}{7,315} & 1.0 \\
\hline $30 \mathrm{MPa}$ & \multicolumn{2}{|l|}{7,238} & 1.6 \\
\hline Table 10 & \multicolumn{3}{|c|}{ Results summary to concrete porosity. } \\
\hline \multirow[t]{2}{*}{ Concrete } & \multicolumn{2}{|c|}{ Average surface porosity } & $\begin{array}{l}\text { Volumetric porosity } \\
(\%)\end{array}$ \\
\hline & MicroCT & Scanner & NBR 9778 \\
\hline $20 \mathrm{MPa}$ & 1.7 & 1.0 & 1.9 \\
\hline $30 \mathrm{MPa}$ & 1.6 & 1.6 & 2.1 \\
\hline
\end{tabular}

what may happen is that some pores are lost or some noise can be considered as pore.

It can be seen that the porosity found for $20 \mathrm{MPa}$ concrete by the method was shown in NBR 9778 and found by analysis of images obtained by microtomgraphy is lower than that found in the $30 \mathrm{MPa}$ concrete. This may be due to changes in the water cement ratio in the feeder of cement truck change the voids in concrete with higher strength, since that the technical literature reports higher values of porosity for concrete with lower resistance. In general, to analyze the compressive strength of the concrete should also be considered the size and distribution of pores; in our samples the $30 \mathrm{MPa}$ concrete has a higher amount of smaller pores.

The use of imaging by microtomography or the use of a scanner (in both cases complemented with techniques of image processing) is shown as viable methods to estimate the concrete porosity. The method using the scanner is presented as an acceptable method for their results, and especially for its low cost and ease operation.

\section{Acknowledgments}

The authors acknowledge the support given by the Carlos Chagas Filho Foundation for Research Support of the State of Rio de Janeiro (FAPERJ), and Embrapa/CNPDIA-San Carlos.

\section{References}

[1] Neville, A. M. Concrete Properties; São Paulo, 1997.

[2] Cook, R. A.; Hover, K. C. Mercury Porosimetry of Cement-Based Materials and Associated Correction 
Factors. ACI Materials Journal 1993, 90(2), 152-161.

[3] ABNT. NBR Hardened Mortar and Concrete-Determination of Water Absorption and Void Index Density, 2005.

[4] Jain, A. K. Fundamentals of Digital Image Processing; Prentice Hall: New Jersey, 1989.

[5] Banon, G. J. F.; Barrera, J. Bases da Morfologia para a
Analysis of Binary Images. INPE, São José dos Campos, 1998.

[6] Meyer, F. Automatic Screening of Cytological Specimens. Computer Vision. Graphics and Image Processing 1993, 35, 356-369.

[7] Lima, I. Histomorphometric Quantification 2D from 3D CT. Master Thesis 2002. 